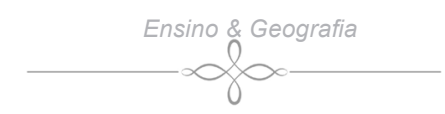

\title{
Contextualizando os conteúdos na perspectiva global- local: uma proposta pedagógica para a disciplina de Geografia
}

\begin{abstract}
Resumo: A escala de abordagem dos conteúdos é uma das muitas problemáticas encontradas no ensino de Geografia, uma vez que a prática pedagógica nesta disciplina escolar se encontra diante da seguinte dualidade: trabalhar os conteúdos numa escala local ou global? Não obstante, quando se analisa a práxis pedagógica predominante nas aulas de Geografia, se constata que esta abordagem tem comumente priorizado o estudo dos fenômenos, processos e paisagens na escala global, não ocorrendo na maioria das vezes uma contextualização destes conteúdos com a realidade cotidianamente vivenciada pelos alunos. Portanto, o presente trabalho expõe de que forma esta dualidade na abordagem dos conteúdos se dá nas aulas de geografia, alertando para a importância da contextualização dos conteúdos e teorias da ciência geográfica ao cotidiano dos alunos, num contexto em que este espaço vivenciado pelos alunos se transforme em um verdadeiro laboratório para as aulas de geografia, contribuindo desta forma para a formação da consciência espacial, condição imprescindível à formação do cidadão crítico e consciente do meio ao qual está inserido.
\end{abstract}

\section{Contextualizing the contents in the perspective global- place: a proposal of pedagogic practice for the Geography discipline.}

\begin{abstract}
The scale of approach of the contents is one of the a lot of problems found in the teaching of Geography, once the pedagogic practice in this school discipline is due to the following duality: to work the contents in a scale local or global? In spite of, when the predominant pedagogic practice is analyzed in the classes of Geography, it is verified that this approach has been prioritizing the study of the phenomena, processes and landscapes commonly in the global scale, not happening most of the time daily an interrelation of these contents with the reality lived by the students. Therefore, this paper exposes how this duality in the approach of content takes place in geography lessons, stressing the importance of content and context of theories of geographic science to everyday life of students in a context in which this space is experienced by students transformed into a veritable laboratory for geography lessons, thus contributing to the formation of spatial awareness, an indispensable condition for the formation of the critical citizen and conscious of the environment to which it is inserted.
\end{abstract}

* Doutorando do Programa de Pós Graduacão em Geografia da Universidade Estadual de Londrina (UEL)

Palavras- chave: Local; Global; Contextualização; Ensino de Geografia; Espaço Vivido.

Key-Words: Place; Global; Contextualization; Geography Teaching; Lived Space. 


\section{Introdução}

Tradicionalmente nas salas de aulas do Brasil, a Geografia vem sendo apresentada aos alunos como sendo uma disciplina que se preocupa em descrever os mais variados fenômenos ocorridos nas diversas e mais longínquas coordenadas geográficas do planeta, sem dar a importância devida ao estudo do lugar, ou seja, do espaço visível e vivenciado cotidianamente pelos alunos.

A esse respeito, Callai $(2009$, p.83) elucida o fato de que "muitas vezes sabemos coisas do mundo, [...] temos informações de acontecimentos exóticos [...] de vários lugares [...]mas não sabemos o que está acontecendo no lugar em que vivemos".

E esta não é uma problemática exclusiva da contemporaneidade. Prova disso é que Mombeig (1954, s/p.) já alertava para o enciclopedismo da Geografia em meados do século XX:

\footnotetext{
[...] a geografia é uma lembrança extremamente penosa de sua infância. Seu nome evoca listas indigestas de nomes de lugares ou dados numéricos, lições atrozes que somente os menos inteligentes e os mais obstinados de nossos condiscípulos chegavam a recitar razoavelmente [...] a lista das estações da Central do Brasil entre Rio e São Paulo, ou as altitudes exatas dos vulcões andinos; a fraqueza em geografia é uma espécie de teste de inteligência!
}

Assim ao se estudar, por exemplo, os processos geológicos/geomorfológicos de formação e evolução dos relevos nos Andes ou no continente asiático, muitas vezes o professor não aborda como que se deu a constituição do relevo vivenciado cotidianamente pelos alunos, ou ainda, quando se estuda as grandes bacias hidrográficas das Américas, os rios da cidade onde o professor esta lecionando não são estudados. 0 mesmo se aplica a outras áreas de geografia como a geopolítica, a climatologia, a cartografia, etc.

Isto representa dizer que a prática de ensino de Geografia não pode se resumir no estudo descritivo dos fenômenos, processos e paisagens distantes do espaço vivenciado pelos alunos, mas que o lugar também deve ser abordado como um conceito fundamental para a construção da identidade destes, uma vez que segundo Santos (2006, p.338), "cada lugar [por menor que seja] é ao mesmo tempo objeto de uma razão global e de uma razão local convivendo dialeticamente".

Não que o ensino de geografia deva se reduzir em um ensino "regionalista" ou "localista", mas o objetivo nesta prática é aproximar os conteúdos e teorias da geografia ao cotidiano dos alunos, sendo importante estabelecer uma inter-relação do espaço local com os fenômenos, processos e as paisagens da totalidade.

Portanto, o presente trabalho expõe de que forma esta dualidade na abordagem dos conteúdos se dá nas aulas de geografia, alertando para a importância da contextualização dos conteúdos e teorias da ciência geográfica ao cotidiano dos alunos, num contexto em que este espaço vivenciado pelos alunos se transforme em um verdadeiro laboratório para as aulas de geografia, contribuindo desta forma para a formação da consciência espacial, condição imprescindível à formação do cidadão crítico e consciente do meio ao qual está inserido.

Geografia Ensino \& Pesquisa, v. 16, n.2 p. 85 - 100 maio./ago. 2012

Contextualizando os conteúdos na perspectiva global- local: uma proposta pedagógica para a disciplina de Geografia

\section{A importância da contextualização dos conteúdos no ensino de geografia}

Muito tem sido escrito acerca do fato de que a práxis pedagógica deva possuir uma significância real para os alunos, e que esta contribua de forma efetiva para a formação de um individuo crítico, que exerça a cidadania de forma consciente, e que desta forma possa atuar e transformar a realidade na qual está inserido.

Em geografia, esta preocupação assume uma importância sui generis, uma vez que seria impossível cumprir com esse objetivo da educação, se 0 aluno, ao final de seu processo formativo 
não tiver adquirido a consciência espacial do meio ao qual está inserido e a materialização neste do fenomênico global.

A esse respeito Stefanello (2009, p.67) recorda que,

[...] a geografia não estuda a Terra, mas o espaço geográfico [...] onde o homem estiver. Há nesse sentido um importante relação inter-escalar: a geografia trabalha com o local, o regional, o nacional e o global, e todos esses níveis estão relacionados entre si [...].

Até porque, como elucida Santos (2006, p.339), "cada lugar é ao mesmo tempo, objeto de uma razão global e de uma razão local, convivendo dialeticamente.".

$O$ fato é que nota-se que ainda hoje, esta contextualização global-local, que deveria ocorrer nas aulas de Geografia cotidianamente, encontra-se bastante distante da realidade da prática pedagógica de parte significativa do professorado, como sustenta Souza (2007, p.06).

Exemplificando o exposto anteriormente, um dos temas de maior repercussão na atualidade é o chamado aquecimento global, fruto, segundo a maior parte da comunidade cientifica internacional da histórica relação predatória que o homem estabeleceu com a natureza, principalmente no âmbito de sistema capitalista.

Sendo a geografia a ciência que estuda as relações "sociedade/natureza" e pelo fato que essa temática engloba vários conteúdos abordados por esta ciência (clima, vegetação. biogeografia, geopolítica, etc.), o aquecimento global passou a ser um tema muito presente nas aulas de Geografia.

Desta forma o que comumente ocorre é que muitas vezes essa temática é abordada na escola somente ou com maior ênfase na escala global, sem levar em conta os resultados desse evento a nível local, como por exemplo, sua influência para as atividades econômicas, para os rios, para o clima, para o regime de chuvas de um recorte espacial vivenciado pelos alunos.

Isto faz com que os alunos venham a questionar o que eles têm a ver com esse "tal" aquecimento global.

O fato é que ao trabalhar os fenômenos processos e paisagens somente a nível global, acabam fazendo com que os indivíduos (no caso os alunos) não compreendam, ou melhor, não relacionem esse conteúdo com seu espaço cotidiano. E mais, a Geografia,

\begin{abstract}
[...] Caracteriza-se pelo estudo da produção social do espaço entendido como uma das características dos fenômenos. O papel fundamental da geografia no ensino básico é 0 de proporcionar aos alunos os códigos que permitam decifrar a realidade por meio espacialidade dos fenômenos [...]. (PEREIRA, 2003, p.14).
\end{abstract}

Pode estar nessa dificuldade de compreensão da totalidade 0 principal entrave à conscientização para as conseqüências do aquecimento global, por exemplo. Ou ainda, para a própria compreensão do conteúdo específico trabalhado pelo professor.

Neste contexto, "[...] o lugar assume a importância fundamental [...] porque ele é o cotidiano imediato, localmente vivido, portanto, objeto de uma razão global", como aponta Pires, Lindau e Rodrigues (2003, p.25).

Deste modo, se nas aulas de geografia o professor discutir o histórico das relações sociedade/natureza do lugar, assim como que os resultados destas relações locais contribuíram para 0 aquecimento global, além das conseqüências de um problema global para o "cotidiano, o imediato", aí o problema do aquecimento global passa a ser um problema não somente dos governos, dos paises desenvolvidos ou da ONU, mas também do individuo localizado no mais recôndito dos lugares.

Este exemplo do aquecimento global pode ser aplicado a vários outros conteúdos de ciência geográfica, uma vez que na geografia,
Geografia Ensino \& Pesquisa, v. 16, n.2 p. 85- 100, maio./ago. 2012 
[...] o lugar esta presente de diversas formas. Estudá-lo é fundamental, pois ao mesmo tempo em que o mundo é global, as coisas da vida, as relações sociais. [as paisagens] se concretizam nos lugares específicos. [...] compreender o lugar em que vive permite ao sujeito conhecer a sua historia e conseguir entender as coisas que ah acontecem [...] (CALAl 2003, p. 84).

Assim ao estudar os processos geológicos/ geomorfológicos de formação e evolução dos relevos, seria interessante e significativo para os alunos compreender como se formaram o relevo do seu espaço cotidiano, o tipo de solo onde seus pais semeiam, como que se formou a montanha que avistam da janela da sua casa, etc.

Ao se estudar o clima global, porque não trabalhar com os alunos as especificidades do clima local?

O mesmo pode ser feito quando se estuda as grandes bacias hidrográficas mundiais (ou mesmo nacionais), ou seja, estudar os rios existentes no recorte espacial dos alunos.

Sem dúvida esta prática facilitaria a compreensão dos alunos acerca da temática trabalhada, uma vez que eles podem observar in loco o rio, a mata ciliar, se está ou não poluído, sua importância para os moradores do seu entorno etc.

Ao se estudar as grandes florestas globais seria interessante que o professor trabalhasse com os alunos a cobertura vegetal do lugar, sua biogeografia, etc.

Isto tornaria o conteúdo mais atraente para os alunos, além de facilitar o processo de ensinoaprendizagem, uma vez que o professor pode sair da sala de aula e mostrar para os alunos a teoria na prática, tornando o espaço de cotidiano um verdadeiro laboratório para as aulas de Geografia.

Isto em um contexto em que Callai (2009, p.101) expõe que:

Nomes de rios, de cidades, acontecimentos tais como erupções vulcânicas, a ocorrência de vendavais, ciclones e tornados, guerras, guerrilhas, incorporação de áreas por outras nações são informações que fazem parte do dia a dia da maioria das escolas. A grande questão, entretanto, é auxiliar o aluno a organizá-las no sentido de entendimento sobre como tais processos naturais e fenômenos atingem a vida das pessoas.

Esses mesmos procedimentos metodológicos do estudo do lugar podem ser aplicados a outros conteúdos abordados pela ciência geográfica, como a produção do espaço urbano (estudando a própria cidade, o bairro, a rua e as demais formas espaciais), as migrações, a globalização (de que forma 0 processo da pretensa globalização influi nas relações internacionais e como estas se relacionam com o cotidiano do lugar), além de estudar, integrando os aspectos físicos e humanos, a organização sócio espacial do lugar, assim como atuaram (e continuam atuando) os processos sociais/naturais, que delinearam as formas espaciais e as paisagens visíveis e vivenciadas pelos alunos.

$E$ tudo isto em um contexto em que "[...] se entremisturam, [...] fluxos regionais, nacionais, multinacionais sobre as particularidades de cada situação local". (LACOSTE, 2006, p.91).

Isto fica bastante evidente nas constatações de Hardwick et. al. (1996), que ao discorrer acerca das múltiplas escalas em que se processam o fenomênico, além das múltiplas inter-relações dos mesmos, elucida que:

Geografia Ensino \& Pesquisa, v. 16, n.2 p. 85 - 100 maio./ago. 2012

Contextualizando os conteúdos na perspectiva global- local: uma proposta pedagógica para a disciplina de Geografia

A mídia nos relembra a cada dia que somos todos membros de uma sociedade global. Dependemos de pessoas de outras regiões do nosso país e do globo. Porém, quanto sabemos sobre outros lugares? Será que nossos homens de negócios e líderes políticos conhecem o suficiente a respeito dos povos e da superfície deste planeta? Muitas das mais largas corporações do mundo hoje em dia são multinacionais. Bancos, empresas extrativas, firmas de vendas na atualidade dependem do mercado global. Os professores com freqüência usam uma visita ao shopping center local como uma lição de geografia, examinando os rótulos dos produtos para enfatizar a influência internacional sobre as nossas vidas diárias. E inversamente, produtos norte-americanos estão difundidos através do mundo: por exemplo, certos restaurantes do tipo fast food existem atualmente em praticamente todas as maiores cidades do mundo(...) 
Fica desta forma evidente que esta contextualização global-local emerge na sociedade globalizada de hoje como uma prova cabal desta entremistura de fluxos que acabam por interconectar os espaços e interferir no cotidiano imediato das pessoas.

E a prática contextualizadora não faz outra coisa senão demonstrar aquilo que já ocorre neste cotidiano, no espaço vivenciado pelas pessoas.

Isto torna o conteúdo (a própria geografia) mais atraente para os alunos, além de facilitar o processo de ensino-aprendizagem, uma vez que neste caso o professor tem a possibilidade de demonstrar in loco os conteúdos e teorias da ciência geográfica através dos fenômenos e paisagens do espaço visível e vivenciado pelos alunos no seu cotidiano, num contexto onde:

\begin{abstract}
O espaço é cheio de história [...]. A história está cristalizada, materializada no espaço, seja pelas edificações, pelo tipo de arquitetura, pela forma de organização dos espaços urbanos, pela organização dos bairros, pelas indústrias, pela circulação e transportes, pelos desmatamentos, pelas lavouras, pelos solos desgastados, pelos tipos de lavouras, pela estrutura fundiária. Ao viver nossa vida enfim, construímos o espaço, pois nele fica marcada toda a história da vida humana. (AIGNER, 2003, p. 63).
\end{abstract}

Cabe ressaltar que ao trabalhar os conteúdos e teorias da geografia numa escala local não significa que o ensino da ciência geográfica deva caminhar para um "regionalismo" ou um "localismo", desconsiderando como importante esses fenômenos em escala global.

0 que deve ficar bem claro é que tanto o estudo dos fenômenos, processos e paisagens globais, quanto os mesmos aspectos a nível local são importantes, e que o professor de geografia deve estabelecer uma espécie de "ponte", uma conexão entre os fenômenos e as paisagens globais com o mesmo aspecto do recorte espacial do cotidiano dos alunos, onde o lugar se transforma num verdadeiro laboratório para a compreensão dos fenômenos, processos e das paisagens da totalidade.

Não obstante, cabe ressaltar que esta práxis se torna justificável quando esta leva em conta o exposto por Diniz (2009, p.169-170), onde a percepção pessoal dos alunos, aliados a cientificidade dos conteúdos acabariam por facilitar a compreensão dos fenômenos, tendo em vista que as relações espaciais dos educandos se dão em espaços reduzidos, ou seja, o lugar, onde também reverbera a lógica global.

Nesta mesma vertente, Lacoste (2006, p.77) aponta que "a "realidade" aparece diferente [...] segundo os níveis de análise [...] [e que] a mudança de escala corresponde a uma mudança no nível de conceituação". E porque não acrescentarmos também uma mudança no nível de compreensão por parte dos alunos?

Isso porque quando o aluno estuda um determinado conteúdo somente na escala global, desprezando suas implicações no recorte das suas relações espaciais, sua compreensão pode ser distinta da abordagem que contempla também o lugar vivenciado cotidianamente por ele.

$E$ isto quando esta abordagem nada convencional não colabora para que o aluno não atinja a compreensão da totalidade em Geografia, desconhecendo as inter-relações entre as diversas porções espaciais nas suas múltiplas dimensões e escalas.

Mas nem tudo parece ser um mar de tranqüilidade quando o professor efetivamente trabalha com esta contextualização global-local no seu cotidiano escolar.

O próprio Lacoste $(2006$, p.82) chama a atenção para a problemática da escala de abordagem dos fenômenos, uma vez que "[...] é preciso estar consciente que são fenômenos diferentes porque eles são aprendidos em diferentes níveis de análise espacial.".

Nesse contexto, não basta que o professor reduza a contextualização a uma simples menção de fatos ou fenômenos do local para dizer que estabeleceu uma interconexão com a escala do local.
Geografia Ensino \& Pesquisa, v. 16, n.2 p. 85- 100, maio./ago. 2012

Souza, M. A.

ISSN 2236-4994 | 93 
${ }^{1}$ Conforme Lacoste (2006, p.83)

Antes, esta contextualização deve estar pautada sobretudo, num exercício de "[...] diferenciação e de articulação sistemáticos"1 destes fenômenos com as diferentes escalas de representação, para que de fato ocorra esta interconexão.

Callai $(2009$, p.84) sugere por sua vez que, em "muitas vezes as explicações podem estar fora, sendo necessário buscar motivos tanto internos quanto externos para se compreender o que acontece no lugar".

Outro ponto a ser destacado é o fato de que se já é difícil um professor licenciado em geografia trabalhar os conteúdos de forma integrada no contexto de uma prática pedagógica multiescalar, o que não dizer dos professores licenciados em outras ciências que lecionam geografia, uma problemática muito mais comum do que se imagina nas escolas brasileiras.

Este fato deve ser levado em conta, como aponta Souza (2007, p. 06), tendo em vista de que são grandes as dificuldades encontradas por esses professores substitutos ao lecionarem geografia, uma vez que estes não dominam vários conteúdos desta disciplina, principalmente aqueles relacionados a parte física da geografia (climatologia, geomorfologia, hidrografia, etc.), além da própria cartografia.

E ao não dominarem esses conteúdos, acabam reproduzindo este "não saber" para os alunos, uma vez que conforme constatou Souza (2007, p.12), estes professores tendem a ter uma prática pedagógica deficiente para com os objetivos do ensino de geografia.

Prática esta que engloba na maioria dos casos a simples memorização de vários conteúdos os quais nem eles próprios dominam, o que faz com que a tão almejada "síntese geográfica" não ocorra, tampouco a inter-relação dos fenômenos que ocorrem globalmente com a realidade vivenciada pelos alunos, fazendo com que a disciplina de geografia se resuma a descrição e a memorização dos textos dos livros didáticos que retratam uma série de fenômenos ocorridos nas mais variadas latitudes do planeta.

Paralelamente a estas constatações, outra prática pedagógica que visa romper com a práxis que privilegia a abordagem "globalista" dos fenômenos, emerge da importância da interdisciplinaridade, para se compreender os fenômenos ao nível do local.

Isto representa dizer que qualquer prática que se interponha a não contextualização dos conteúdos com a realidade vivenciada cotidianamente pelos alunos, contraria o cumprimento dos objetivos da educação como um todo.

E já que na teoria o processo educativo visa formar um cidadão crítico, ativo e transformador, este deve "saber pensar o espaço para saber nele se organizar, para ali combater" (LACOSTE, 2006, p.189).

Isto porque se o aluno não for capaz de compreender a sua realidade no que tange a espacialidade dos fenômenos vivenciados no seu cotidiano, seria muito difícil, porque não dizer impossível formar um aluno com senso crítico e participação ativa na construção/transformação da sua realidade, que vive influenciada pelo fenomênico global, senão vejamos o exposto por Vesentini (1993, p.41) aponta que,

Ser cidadão pleno em nossa época significa antes de tudo estar integrado criticamente na sociedade, participando ativamente de suas transformações. Para isso, devemos refletir sobre o nosso mundo, compreendendo-o do âmbito local até os âmbitos nacional e planetário. E a Geografia é um instrumento indispensável para empreendermos essa reflexão, que deve ser a base de nossa atuação no mundo em que vivemos.

Geografia Ensino \& Pesquisa, v. 16, n.2 p. 85 - 100 maio./ago. 2012

Contextualizando os conteúdos na perspectiva global- local: uma proposta pedagógica para a disciplina de Geografia

94

ISSN 2236-4994
E na medida em que o lugar emerge com uma importância irrefutável, como uma das partes que compõe o todo, o professor terá de tornar significativo para os alunos a apreensão destes conteúdos numa abordagem inter-escalar, buscando uma contextualização entre o conteúdo [...] a ser ensinado e a realidade do educando, fazendo com que tal fenômeno se torne um caso que 0 aluno precise ajudar a resolver, chamando-o, dessa forma a responsabilidade com o que ocorre no planeta [...]. (STEFANELLO, 2009, p.67). 
É a partir desta abordagem contextualizadora, que os fenômenos, processos e paisagens expressos nos conteúdos vão se tornando significativos para os educandos, contribuindo assim para a formação do tão propalado cidadão crítico e cônscio do mundo ao qual está inserido.

\section{Trabalhando com os princípios geográficos como referencial teórico para os encaminhamentos metodológicos da práxis contextualizadora.}

De acordo com Nogueira e Carneiro (2009, p.06), data do período histórico de estruturação da geografia cientifica o delineamento dos chamados princípios geográficos, formulados por vários clássicos, que buscavam conferir à Geografia o status de ciência.

Embora estes estejam muito mais ligados a área da produção cientifica do que o ensino propriamente dito, é interessante o professor resgatar a sua utilização também nas suas aulas, sendo estes instrumentos imprescindíveis à práxis contextualizadora.

O primeiro desses princípios, o da "extensão-delimitação-localização" formulado por Ratzel postula que é necessário delimitar o fenômeno a ser estudado, localizando-o na superfície terrestre.

E se 0 professor deseja implementar esta práxis contextualizadora, evidentemente deve delimitar as escalas as quais deseja contextualizar. Não só as escalas, mais diferentes processos, fenômenos e paisagens ocorridas em diferentes espaços do global.

Nesse contexto urge a delimitação desta unidade de área do local a ser compreendida, contextualizada com os elementos acima citados estudados ao nível global.

Então, qual seria o espaço localmente vivido pelos alunos? A municipalidade? A zona rural? 0 bairro? A rua?

São questionamentos que o professor irá respondendo a partir das suas delimitações, dos espaços escolhidos por este para serem contextualizados com a realidade global.

Humboldt por sua vez formula o principio geográfico da "causalidade", segundo o qual, além da simples localização dos fenômenos na superfície terrestre, aponta que deve haver uma explicação, uma causa que explique o "porquê" dos fatos.

Por que no entorno das indústrias da "minha cidade" habitam majoritariamente operários? Por que os conjuntos habitacionais estão longe do centro da cidade? Porque na cidade ao qual habito não existem terremotos enquanto o Haiti, o Japão e o Chile são assolados por este fenômeno natural?

São exemplos de questionamentos cujas respostas somente podem possuir uma explicação geográfica se analisado o principio da causalidade. Até porque a configuração espacial da cidade onde os alunos habitam só se fez possível através de uma causa específica, e não por uma mera obra do acaso.

Já o principio da "analogia", formulado por Karl Ritter e Paul Vidal de La Blache postula que nos estudos geográficos há a necessidade de se comparar os fatos, os fenômenos ou ainda a porção do espaço geográfico estudada com outras áreas, fatos e fenômenos, com o objetivo de se estabelecer diferenças ou semelhanças existentes entre os objetos de comparação.

Será que existem montanhas semelhantes em outras localidades as que eu encontro na cidade a qual resido? Será que todas as cidades do país possuem a mesma configuração espacial da minha? Existirão na Europa as mesmas atividades geoecônomicas do Brasil, ou da cidade a qual habitam os alunos?

Esta é a riqueza do estabelecimento de analogias entre os fenômenos. Comparar a ocorrência ou a ausência de determinados fatos em outras porções espaciais faz com que esta práxis contextualizadora estimule a compreensão da articulação entre os vários fatores que podem ser comuns ou dispares a realidade cotidianamente vivida pelos alunos.

Outro principio geográfico que data deste período de consolidação da geografia científica é o principio da "conexidade", formulado por Jean Brunhes, segundo o qual os fatos estudados

Geografia Ensino \& Pesquisa, v. 16, n.2 p. 85- 100, maio./ago. 2012 
estão inseridos em um sistema de relações dispostos em várias escalas, fazendo-se necessário identificar esses elos de ligação entre eles.

Nesse contexto, a práxis contextualizadora ganha e dá significância aos conteúdos, ao tentar demonstrar, por exemplo, que o espaço econômico europeu não é simplesmente algo que o aluno tem de estudar por estar nos livros didáticos, mas algo que reverbera no cotidiano imediato destes alunos.

Até porque, relembrando o exposto anteriormente, "cada lugar é ao mesmo tempo, objeto de uma razão global e de uma razão local, convivendo dialeticamente.". (SANTOS, 2006, p. 339)

É de Brunhes ainda outro dos princípios geográficos, o da "atividade". De acordo com este principio os fatos apresentam um caráter dinâmico, mutável, e sendo assim, há a necessidade de se analisar o passado da área estudada para se compreender a materialização das atuais formas espaciais e prever as tendências futuras.

Sem a compreensão desta atividade que produz cotidianamente a dinamicidade do processo de produção do espaço geográfico, seria impossível realizar uma abordagem geográfica dos fenômenos.

Até porque, ao não se trabalhar o espaço geográfico sendo moldado por forças endógenas e exógenas ao lugar, naturais e artificiais, engendradas na relação indissociável entre os sistemas de objetos e sistemas de ações tão bem conceituados por Santos (2006, p.63), se estará fazendo qualquer outra coisa, menos Geografia.

Portanto, como esta práxis que visa romper com a abordagem globalista do fenomênico na sala de aula, se torna bastante pertinente o professor de Geografia retomar os muitas vezes esquecidos "princípios geográficos" como referencial teórico para proceder o estudo da realidade cotidianamente vivenciada pelos alunos.

Contextualização esta na qual se torna imprescindível utilizar os princípios da localização, da causalidade, da analogia, da conexidade e da atividade, para que as aulas de Geografia e a implementação desta práxis tenha notadamente um abordagem geográfica dos fenômenos, o que contribuirá efetivamente para a formação da consciência espacial dos alunos.

\section{A prática docente contextualizadora e o rompimento da dicotomia "Geografia Humana versus Geografia Física"}

A evolução histórica do pensamento geográfico e o próprio processo de consolidação da Geografia enquanto ciência acabou por registrar uma dicotomia, aquela que divide a ciência geográfica em Geografia Física e a Geografia Humana. (DINIZ FILHO, 2009, p.41-43).

Esta dicotomia seria fruto de um processo de especialização dos geógrafos em um processo de fragmentação das áreas de estudo, como a "Geografia Agrária", a "Climatologia", a "Geomorfologia", a "Geografia Urbana", a "Hidrografia", a "Geografia da População", dentre outras, o que acabou contribuindo para uma separação entre os estudos da natureza e os estudos das relações humanas e sociais, por assim dizer.

De acordo com esta realidade dicotômica, à Geografia Humana estariam relegados os

Geografia Ensino \& Pesquisa, v. 16, n.2 p. 85 - 100 maio./ago. 2012

Contextualizando os conteúdos na perspectiva global- local: uma proposta pedagógica para a disciplina de Geografia estudos da espacialidade dos fenômenos relacionados aos processos humanos e sociais, tais como urbanização, a questão agrária, a mobilidade populacional pelo território assim como os fluxos migratórios internacionais, a globalização, as relações internacionais e a geopolítica, dentre outros aspectos.

Por outro lado, a Geografia Física é caracterizada como a parte da geografia responsável pelos estudos geográficos relativos ao funcionamento da natureza, ou seja, os processos geológicos/ geomorfológicos de formação e evolução dos relevos, a evolução histórica e as implicações territoriais das variações climatológicas, a hidrografia, a biogeografia, a pedologia, dentre outros fatores. 
O fato é que não é de agora que muitos geógrafos, preocupados dentre outras coisas com a própria identidade da ciência geográfica ou a sua postura enquanto ciência consolidada, vem apontando a necessidade de se buscar mecanismos de integração entre estas duas subdivisões da ciência geográfica, o que também implicaria esta contextualização ao nível escolar.

Nesse contexto em que se aponta a importância da contextualização dos conteúdos a escala do local vivenciado pelos alunos, o rompimento desta dicotomia emerge ainda como um dos obstáculos a serem removidos inclusive no ensino desta disciplina.

Isso em um cenário onde a Geografia Humana é apresentada aos alunos como sendo uma "subdivisão da ciência geográfica" completamente distinta da Geografia Física, ou ainda, como se os sistemas de objetos e os sistema de ações não fossem elementos indissociáveis no espaço geográfico, como elucida Santos (2006, p.63).

E esta práxis pedagógica que visa a romper com esta cisão histórica, que inclusive empobrece a análise espacial, deve ser praticada no âmbito de um processo que além de contextualizar os conteúdos da chamada "Geografia Humana" com a denominada "Geografia Física", também deve contextualizar as diferentes escalas de abordagens dos fenômenos espaciais.

É impossível compreender o processo de ocupação de um determinado local, sem levar em conta os elementos da natureza, que explicariam, por exemplo, o porque das regiões de extremos climáticos, como o deserto do Saara ou a Sibéria por exemplo, apresentarem baixíssimas densidades demográficas.

Não obstante, os estudos climatológicos, supostamente relegados a "Geografia Física" já vem incorporando com uma força avassaladora a intervenção humana na produção da sua existência, nos seus estudos sobre as mudanças climáticas.

O mesmo poderia ser aplicado aos estudos relativos as condições ambientais da rede hidrográfica de uma determinada localidade, da ocupação desordenada dos fundos de vale e dos morros frente aos fenômenos da natureza, como as intensas chuvas que castigam as periferias mal localizadas dos grandes centros brasileiros.

Nesse contexto, nota-se que é impossível dissociar as relações humanas dos eventos da natureza, como se a interação entre ambos não fosse um elemento significativo para a análise geográfica, ou ainda, que não tivessem nenhuma ligação.

Assim, ao trabalhar com os processos geológicos/geomorfológicos da formação e evolução dos relevos, seria interessante o docente inserir as relações humanas neste processo.

Desta forma, o intemperismo biológico, o processo de ocupação desordenada de morros, e 0 estabelecimento de relações entre a ocupação humana e as condições topográficas de determinadas porções do espaço geográfico poderiam ser algumas das múltiplas sugestões de encaminhamentos metodológicos para o rompimento desta dualidade, nesta temática especifica.

Quando se trabalhar os conteúdos relacionados com hidrografia continental e oceânica, nada melhor que incluir a relação dos seres humanos que habitam o seu entorno com os rios, lagos e mares, com suas condições ambientais, ou ainda com a própria cultura de seus moradores.

Não obstante, o mesmo deveria ocorrer com os estudos relativos à chamada Geografia Humana.

Ao se estudar a densidade demográfica de um determinado local, não há como dissociá-lo dos fenômenos naturais, como os extremos climáticos, a topografia, e demais acidentes geográficos, como vulcões, furacões e terremotos, por exemplo.

0 mesmo deveria ser aplicado aos estudos da geopolítica. Se como aponta Lacoste (2006, p. 28-29), que o relevo, a hidrografia, a vegetação são elementos transcendentais numa guerra, como dissociar os fatores naturais para a compreensão das estratagemas de um conflito militar, comumente estudados somente no âmbito das relações internacionais ?

Portanto, o professor ao buscar romper com esta prática ainda presente nas universidades e nas escolas, deve levar em consideração o exposto por Santos (2006, p.63), onde:

Geografia Ensino \& Pesquisa, v. 16, n.2 p. $85-100$, maio./ago. 2012 
O espaço é formado por um conjunto indissociável, solidário e também contraditório, de sistemas de objetos e sistemas de ações, não considerados isoladamente, mas no quadro único no qual a história se dá. No começo era a natureza selvagem, formada por objetos naturais, que ao longo da história vão sendo substituídos por objetos fabricados [...] Sistemas de objetos e sistemas de ações interagem. [...] É assim que o espaço encontra a sua dinâmica e se transforma.

Portanto, além de o professor realizar uma contextualização dos fenômenos abordados comumente na escala global, seria importante também contemplar uma prática pedagógica que possibilitasse o rompimento da dicotomia "Geografia Física" e "Geografia Humana", como forma de cumprir os objetivos da educação como um todo, especificamente formar cidadãos críticos e conscientes do mundo ao qual estão inseridos, podendo intervir na sua realidade.

\section{Práticas e recursos pedagógicos: instrumentalizando a contextualização}

É consenso entre os educadores de diferentes correntes de pensamento que o livro didático, embora seja um instrumento de grande valia no âmbito do processo de ensino-aprendizagem, não é suficiente para que se cumpram os objetivos educacionais como um todo. Principalmente quando se trata da contextualização dos conteúdos à realidade dos alunos.

Isto ocorre em grande medida, devido ao fato de que a construção do livro didático privilegia uma escala maior de conceituação do fenomênico, ou seja, o espaço mundial e o território do estado-nação, e quando muito a divisão político-administrativa estadual, na qual está inserido a municipalidade do aluno.

Nesse contexto, Stefanello (2009, p.70) elucida que caberá ao professor empreender esta inter-relação entre as múltiplas escalas onde reverberam estes conteúdos trabalhados em sala de aula, mais especificamente à realidade dos alunos.

$O$ fato é que como já foi abordado anteriormente, esta abordagem que se reduza a escalas alheias a realidade dos alunos, acaba por fazer da Geografia uma disciplina pouco significativa, sendo bastante comum ouvir dos alunos alguns questionamentos do tipo, "Porque eu estudo a dados do relevo da Ásia, se eu moro no Brasil?"

É óbvio que é importante estudar estes conteúdos alocados geograficamente em escalas maiores de abordagem, mas este conteúdo acaba não sendo significativo para o aluno se este não vem acompanhado de uma contextualização com a realidade vivida dos alunos, e ainda de uma práxis que rompa com a dualidade "Geografia Física e Geografia Humana".

E isto não é uma tarefa fácil. Para que tais contextualizações sejam feitas de forma efetiva, é necessário que o professor domine os conteúdos de forma ampla, e não somente tenha memorizado alguns trechos do livro didático, que deve ser encarado no processo de ensino-aprendizagem como uma fonte de apoio para as suas aulas, e não como único instrumento para o docente preparar as aulas, e como única fonte de informações para os alunos.

Urge então aos professores que busquem a cientificidade dos conteúdos para que dominem

Geografia Ensino \& Pesquisa, v. 16, n.2 p. 85 - 100 maio./ago. 2012

Contextualizando os conteúdos na perspectiva global- local: uma proposta pedagógica para a disciplina de Geografia tais conteúdos e possam reconhecer no cotidiano de seus alunos as teorias cientificas que dão corpo a Geografia.

As teorias da Geologia, dos processos de formação e evolução dos relevos não se aplicam exclusivamente às zonas em que ocorrem terremotos, vulcanismos e tsunamis nos Andes ou no Himalaia. Ao contrário, explicam ainda a constituição geológica/geomorfológica do chão que se pisa cotidianamente, a topografia do sítio urbano no qual está assentado a cidade do aluno, o tipo de solo em que seus pais praticam a agricultura, etc.

O mesmo se aplica aos outros conteúdos da Geografia. Mas como o professor pode então instrumentalizar para que esta contextualização se materialize de forma efetiva? 
Primeiramente é preciso o docente em sua prática pedagógica estar aberto a utilização de uma série de recursos didáticos pedagógicos no cotidiano de suas aulas.

A esse respeito Callai $(2009$, p.88) sugere que "O estudo do lugar pode se estender para muito além do texto. E pode-se utilizar outros recursos como a observação da paisagem ao vivo ou a uma figura desta mesma paisagem, fotografias, vídeos, filmes, etc".

Dentre estes múltiplos recursos pedagógicos que devem ser incorporados ao cotidiano da prática docente do ensino de Geografia está o trabalho de campo.

Autilização do trabalho de campo emerge como um importante encaminhamento metodológico às aulas de Geografia à medida que é a partir deste que os alunos têm a possibilidade de observar in loco as teorias estudadas na sala de aula.

Os alunos podem estar em contato cotidianamente com estas porções espaciais que por ventura poderão ser objeto de análise no trabalho de campo.

Mas no trabalho de campo, o professor assume uma postura de mediador entre aquela teoria pouco significativa do longínquo, transpondo-a para aquela realidade em específico, mostrando as inter-relações e as diferenças entre ambas escalas de abordagem.

É importante que a aula de campo seja preparada com anterioridade, e não seja baseada na improvisação, porque se assim for, não cumprirá com objetivo da utilização deste recurso pedagógico.

Se o professor não instrumentalizar a observação, atuando como mediador, os alunos encararão como uma mera excursão, e a abordagem geográfica não se realiza na sua essência.

Tampouco a explicação da realidade local deve ser explicada simplesmente através da descrição do observado, mas os alunos deverão buscar em várias fontes bibliográficas teorias que expliquem aquela realidade.

Não obstante ao trabalho de campo, existem muitas outros recursos a serem utilizados pelo professor. Os recursos audiovisuais ( filmes, obras de arte, obras literárias, fotografias, charges, reportagens jornalísticas, música, etc), emergem como importantes aliados do professor no ensino de Geografia.

Aqui cabe uma ressalva válida para todos os recursos pedagógicos a serem utilizados pelo professor: eles devem possuir um objetivo educacional aliado aos conteúdos estudados.

Quando se fala em filmes e músicas não se está referindo a qualquer filme ou a qualquer música. Antes há que ficar muito claro tanto para o professor quanto para o aluno que a utilização destes recursos deve ocorrer de maneira combinada aos objetivos pedagógicos do conteúdo.

Isso é bastante pertinente porque se constata que há uma banalização na utilização destes recursos, e na maioria das vezes sua utilização se justifica pelos professores como uma mera ilustração do conteúdo trabalhado.

Quando se trata da contextualização dos conteúdos às diferentes escalas de abordagem, a utilização da fotografia emerge como um importante instrumento de ensino da evolução histórica das paisagens por exemplo.

Ao se analisar, por exemplo, fotografias de diferentes períodos históricos de uma determinada porção do espaço geográfico, é possível compreender a transformação das paisagens, além de reconhecer que locais conhecidos pelos alunos sofreram um processo de metamorfose provocado pela interação dos sistemas de objetos (natureza, cultura, formas espaciais), com os sistemas de ações (ação humana) . (SANTOS, 2006, p.63).

Músicas que abordam a realidade local, obras literárias de artistas locais, assim como reportagens de jornais de circulação regional ou até mesmo local podem ser considerados importantes instrumentos de ensino que favorecem a contextualização.

Outro importante recurso pedagógico a ser utilizado pelo professor é a memória viva, instrumento através do qual se torna possível interagir com atores que vivenciaram as transformações socioespaciais, através dos relatos de suas experiências de vida.

Geografia Ensino \& Pesquisa, v. 16, n.2 p. 85- 100, maio./ago. 2012

Souza, M. A.

ISSN 2236-4994 | 99 
Não é demais lembrar que nenhum destes recursos pode significar a "coisificação" do professor, ou melhor, nenhum deles é capaz de por si só atuar de forma isolada, no sentido de substituir a práxis docente.

O professor continua sendo o principal mediador entre as teorias e o aluno, e os recursos pedagógicos acabam apenas instrumentalizando esta mediação, contextualizando sempre que possível os conteúdos da Geografia à realidade cotidianamente experenciada pelos alunos.

\section{Cartografando o lugar para adquirir uma consciência espacial}

A questão da localização, da representação espacial por meio das linguagens cartográficas, ocupa um lugar extremamente importante na geografia, estando os mapas, plantas, cartas topográficas e maquetes, comumente presente nas aulas de geografia. $O$ fato é que em muitos casos os alunos apresentam dificuldades para compreender os mapas, os quais são considerados por eles como figuras meramente ilustrativas. Assim,

\footnotetext{
"Para que uma criança faça uma leitura de mapas é recomendado que tenha inicialmente aprendido a construí-los [...] a elaboração de um mapa envolve o conhecimento do espaço geográfico, e sua codificação é que traduz em imagem [linguagem semiótica] o significado [...] a leitura dos mapas, indispensável na compreensão espacial envolve o inverso de sua construção, ou seja, a decodificação dos conteúdos de forma significativa e com possíveis significações." (CASTROGIOVANNI, 2003, p. 37).
}

Nesse contexto em que para ler as representações cartográficas é necessário saber construílos, é fundamental que o professor de geografia trabalhe com os alunos a produção de mapas, e mapear o espaço do cotidiano é a forma mais fácil para este exercício. E o que mapear?

Ora como foi visto anteriormente, o espaço visível e vivenciado pelos alunos é um verdadeiro laboratório para as aulas de geografia, assim vários são os aspectos do "lugar" passíveis de serem representados cartograficamente, como a rua, a escola, a cidade, bacias hidrográficas, a biogeografia de uma região, o clima, os índices pluviométricos, as atividades econômicas, etc.

Este exercício é interessante porque possibilita que os próprios alunos levantem e trabalhem os dados, construam as legendas, calculem as escalas, executem as noções de orientação/ localização, o que possibilita, uma vez que compreendam o processo de produção dos mapas, fazer a leitura das representações cartográficas, e "transpor suas informações para o uso cotidiano", como assinala Castrogiovanni (2003, p.39).

Não obstante, seria bastante interessante o docente trabalhar com o mapeamento na escala do local, o que tornaria o próprio processo de compreensão dos elementos cartográficos mais eficazes através da prática in loco da mensuração, da construção das escalas, das decisões acerca dos signos e dos símbolos a serem utilizados na construção da escala, enfim da própria produção e leitura cartográfica.

O que deve ficar bem claro é que a partir do momento em que o professor comece a trabalhar

Geografia Ensino \& Pesquisa, v. 16, n.2 p. 85 - 100 maio.lago. 2012

Contextualizando os conteúdos na perspectiva global- local: uma proposta pedagógica para a disciplina de Geografia

100

ISSN 2236-4994
As formas mais usuais de se trabalhar com a linguagem cartográfica na escola é por meio de situações nas quais os alunos têm de colorir mapas, copiá-los, escrever os nomes dos rios ou cidades, memorizar informações neles representadas. Mas esse tratamento não garante que eles construam os conhecimentos necessários tanto para ler mapas como 
para representar o espaço geográfico [...] A escola deve criar oportunidades para que os alunos construam conhecimentos sobre essa linguagem nos dois sentidos: Como pessoas que representam e codificam o espaço e como leitores das informações expressas por ele." (BRASIL, 1997, p. 118-119).

Não obstante, a cartografia deve significar para o aluno, não somente a compreensão da leitura de realidades distintas e longínquas da sua, mais sobretudo mapear material e abstratamente a sua realidade, de modo que possa compreender todo o processo de produção do espaço geográfico e ao final do processo de ensino-aprendizagem, identificar no seu cotidiano a geograficidade do fenomênico, além de "[...] saber pensar o espaço para nele se organizar [...]" (LACOSTE, 2005, p.189) como ator social ativo.

\section{Da problematização dos conteúdos à pesquisa-ação em geografia}

Uma das vantagens ao se estudar o espaço vivenciado pelos alunos é que eles acabam entrando em contato com um espaço socialmente e historicamente construído no âmbito das relações sociedade/natureza, nos quais englobam modo de produção, processos sociais diversos, relações afetivas com os lugares, etc. Desta forma os alunos passam a ter uma visão diferenciada acerca dos problemas do cotidiano, uma vez que compreendem a gênese e a evolução histórica, bem como as causas e conseqüências do problema em questão. 0 mesmo poderia não ser possível se os conteúdos e teorias da geografia se resumissem apenas na descrição dos fenômenos, processos e paisagens globais.

Assim, Callai (2009, p.84) elucida que se o espaço geográfico resulta da produção histórica dos atores sociais que nele habitam, estudar a realidade vivenciada cotidianamente pelos alunos acaba por resgatar a identidade e o sentimento de pertencimento, além da noção de que ele próprio está e continuará atuando até que se extingua a sua existência física, na construção deste espaço.

Nesse contexto a atuação dos alunos no seu espaço vivido, possibilita que eles passem a ter respostas para os problemas da sua comunidade, uma vez que as aulas de geografia serviriam de arcabouço teórico-metodológico para a investigação, auto-reflexão e a práxis uma vez que:

\begin{abstract}
A Geografia tem enorme contribuição para dar no sentido de ampliar a leitura do mundo e de instrumentalizar a sociedade para a transformação do cotidiano vivido [...] A leitura do mundo passa por saber olhar o espaço local, interpretar as relações entre todas as coisas do lugar na vida cotidiana [...] e entender a dinâmica dessas relações e quais podem ser modificadas para transformar o ambiente onde se vive. (AIGNER, 2003, P. 46)
\end{abstract}

Ao trabalhar, por exemplo, sobre a hidrografia do município, é interessante que os alunos vão a campo conhecer os rios, investigar se o rio está ou não poluído, se a mata ciliar está ou não adequada para as dimensões deste rio, etc. Os alunos podem ser divididos em grupos, onde cada grupo ficaria responsável em pesquisar vários aspectos referentes ao rio, investigando as condições físicas, questionando os moradores, autoridades responsáveis por recursos hídricos, etc.

É através destas pesquisas que os alunos vão tomando consciência dos problemas do lugar, e que tipo de relação esta realidade cotidianamente vivida pode ter com outros espaços, facilitando a compreensão da totalidade além de ter a possibilidade de agir ou ao menos sugerir formas de ação para resolver os mais diversos problemas da sua comunidade.

Os alunos podem mapear áreas poluídas, desmatadas, o destino do lixo produzido na cidade (ou até mesmo no bairro, na escola, etc.), desenvolver projetos de reciclagem, conscientização comunitária, etc.

Desta forma o professor ao trabalhar um determinado conteúdo de geografia deve problematizar este conteúdo, trabalhado-o também na escola do espaço do cotidiano dos alunos,
Geografia Ensino \& Pesquisa, v. 16, n.2 p. 85- 100, maio./ago. 2012

Souza, M. A.

ISSN 2236-4994 101 
cabe ressaltar que neste caso, um instrumento de ensino muito interessante para ser utilizado pelo professor é a pesquisa ação. Isto porque através da integração teoria e pratica os alunos podem atuar como agentes de transformação na própria comunidade em que vivem atingindo através de geografia um papel ativo na sociedade:

\begin{abstract}
A pesquisa-ação é centrada na ação e o papel do pesquisador [alunos-pesquisador] é ativo. É uma ação emancipatória de um grupo social popular [...] que visa resolver algum problema, alguma questão [...] o conhecimento adquirido durante o processo, eleva 0 nível de consciência, o estado de resolução do problema levantado em decorrência da situação estudada. (PIRES, LINDAU \& RODRIGUES, 2003, p. 23 - 24).
\end{abstract}

Até porque, como aponta Callai (2009, p. 84-85), "[...] o lugar é repleto de história e com pessoas situadas num tempo e num espaço [...], e compreender esta história, permite compreender a dinamicidade da produção do espaço geográfico".

Portanto uma geografia que busca estudar o espaço visivel e vivenciado pelos alunos, além de investigar os fenômenos, processos e paisagens do cotidiano através da pesquisa-ação, acaba por contribuir para a formação de cidadãos capazes de compreender o mundo em que vivem e atuar nele de forma mais consciente.

\title{
Considerações finais
}

Atualmente com o processo de globalização, há uma tendência de se homogeneizar os espaços, nas mais diversas leituras de mundo que se tem feito, seja pela mídia ou até mesmo no meio acadêmico, reverberando no processo de ensino-aprendizagem.

O fato é que "no entanto, o lugar assume importância fundamental no processo de globalização, porque ele é o cotidiano imediato, localmente vivido, portanto objeto de uma razão global". (PIRES, LINDAU \& RODRIGUES, 2003, p. 12).

Por mais recôndito que seja o lugar, por menor fração de território que ocupe no país, a compreensão do lugar é peça fundamental para a compreensão da totalidade em geografia, uma vez que "(...) a vida e a experiência das pessoas se prendem nos lugares, em sua cultura, em sua história". (AIGNER, 2003, p. 48).

Não basta em geografia que os alunos tenham de compreender (e em certas ocasiões memorizar) as variadas descrições de aspectos físicos e humanos das mais diversas coordenadas geográficas do planeta, as capitais de todos os países de mundo, etc., uma vez que por mais importante que venham a ser estes conhecimentos "enciclopedistas", na prática, eles não conseguem explicar os fenômenos, processos e as paisagens do cotidiano do aluno, e conseqüentemente não cumprem com os objetivos da educação como um todo, que é formar cidadãos críticos e conscientes do meio ao qual estão inseridos.

Nesse contexto estudar o lugar em geografia é compreender os processos, fenômenos e paisagens que ocorrem numa fração da totalidade, o que permite com a compreensão do que antes parecia ser alheia a realidade dos alunos, um conteúdo sem nenhuma ligação com o espaço visível

Geografia Ensino \& Pesquisa, v. 16, n.2 p. 85 - 100 maio./ago. 2012

Contextualizando os conteúdos na perspectiva global- local: uma proposta pedagógica para a disciplina de Geografia e vivenciado por eles, o que torna a geografia uma disciplina desinteressante, excessivamente descritiva e sem uma atuação pratica.

Por outro lado, a proposta da "pesquisa-ação" vem engajar os alunos a por em prática no espaço em que vivenciam cotidianamente o conhecimento teórico obtido nas aulas de Geografia, que se torna mola propulsora para a investigação, reflexão e atuação na proposição de resolução dos problemas da sua comunidade, formando cidadãos, que ao conhecer a dinâmica dos espaços vivenciados por eles cotidianamente, possam agir de forma consciente na produção e organização desses espaços. 


\section{Referências}

AIGNER, Carlos Henrique. Educação Popular em Porto Alegre: Geografia e Cidadania. In: PIRES, Claudia et.al.(org). Um Pouco do Mundo Cabe nas Mãos: Geografizando o Global e o Local. Porto Alegre: UFRGS Editora, 2003, p.37-56.

BRASIL. Secretaria Do Ensino Fundamental, Ministério da Educação e Cultura. Parâmetros Curriculares Nacionais: História e Geografia. Brasília: MEC/SEF, 1997.

CALLAI, Helena C. Estudar o Lugar para Compreender o Mundo. In CASTROGIOVANNI, A. C. CASTROGIOVANNI A.C. (org). Ensino de Geografia: práticas e textualizações no cotidiano. Porto Alegre: Mediação, 2009.

CASTROGIOVANNI, A. C. Apreensão e compreensão do espaço geográfico. Porto Alegre: Mediação, $3^{\mathrm{a}}$ ed., 2000.

HARDWICK, Susan W., HOLTGRIEVE, DONALD G. Geography for educators. Standards, themes and concepts (traduzido). New Jersey, Prentice Hall, 1996. IN: In: VESENTINI, W. J. Geocrítica Geopolítica: Ensino de Geografia. Disponível em <http://www.geocritica.com.br/texto09.htm >. Acesso em 10 set. 2009.

LACOSTE, Yves. A Geografia - Isso serve em primeiro lugar, para fazer a guerra. São Paulo: Papirus, 2006.

MOMBEIG, P. Papel e valor do ensino da geografia e de sua pesquisa. In: VESENTINI, W. J. Geocrítica - Geopolítica: Ensino de Geografia. Disponível em <http://www.geocritica.com.br/ texto09.htm >. Acesso em 10 set. 2009.

NOGUEIRA V, CARNEIRO, S.M.M. Educação geográfica e formação da consciência espacialcidadã: contribuições dos princípios geográficos. In: Boletim de Geografia. Maringá, UEM, 2008. Disponível em <http://periodicos.uem.br/ojs/index.php/BolGeogr/article/viewArticle/8434 > Acesso em 12 dez. 2009.

PEREIRA, Diamantino. Paisagens, Lugares e Espaços: A Geografia no Ensino Básico. Boletim Paulista de Geografia, n. 79. São Paulo: AGB - SP, jul./2003, p. 9-21.

SANTOS, Milton. A natureza do espaço: técnica e tempo, razão e emoção. São Paulo : Hucitec, 2006.

STEFANELLO, A.C. Didática e avaliação da aprendizagem no ensino de geografia. Curitiba, IBPEX, 2009.

SOUZA, Marcos Antonio de. Os Resultados da "Abordagem Historicista" do Fenomênico no Ensino de Geografia: $O$ caso dos Licenciados... In: IV ENCONTRO DE ENSINO DE GEOGRAFIA/IV MOSTRA DE ESTÁGIO SUPERVISIONADO, 4, 2007, Londrina, Pr. Anais...

VESENTINI, José William. Sociedade \& Espaço. São Paulo, Ática, 1993.

Para uma geografia crítica na escola. São Paulo: Ática, 1993.

Geografia Ensino \& Pesquisa, v. 16, n.2 p. 85- 100, maio./ago. 2012 


\section{Correspondência:}

Marcos Antonio de Souza - Rua Dom Pedro I, 85. Guaraci-PR. CEP. 86620-000

E-mail: geomarcos86@yahoo.com.br

Recebido em 02 de junho de 2011.

Revisado pelo autor em 13 de julho de 2012.

Aceito para publicação em 02 de agosto de 2012.

Geografia Ensino \& Pesquisa, v. 16, n.2 p. 85 - 100 maio./ago. 2012

Contextualizando os conteúdos na perspectiva global- local: uma proposta pedagógica para a disciplina de Geografia

$104 \quad$ ISSN 2236-4994 